\title{
La enseñanza virtual de imágenes clínicas, tutorizada mediante correo electrónico, es más eficiente que la enseñanza tradicional
}

\author{
R.A. Fernández de la Puebla-Giménez, M. de la Mata-García, A. Torres-Gómez, J. Román-Gómez, \\ P. Pérez-Martínez, R. Ruiz-Moral, J. Delgado-Lista, F. Fuentes-Jiménez, J. López-Miranda, F. Pérez-Jiménez
}

Introducción. La enseñanza de la patología médica a través de imágenes es clave para conseguir habilidad clínica en el diagnóstico. Objetivos. Comparar la eficacia docente de un método de enseñanza basado en imágenes en un 'entorno no presencial' frente a la enseñanza tradicional en un 'entorno presencial', y evaluar el grado de satisfacción del alumno sobre este método de innovación docente en la enseñanza de la patología médica. Materiales y métodos. El estudio se realizó durante el curso 2005-2006 entre 62 alumnos de Patología médica, de la Facultad de Medicina de Córdoba. Se compararon los dos métodos de enseñanza: el presencial (en cada seminario se expusieron verbalmente 15 imágenes) y el no presencial (imágenes clínicas expuestas en la página web de la Facultad de Medicina con tutorización a través del correo electrónico). La evaluación consistió en la valoración clínica de 16 imágenes (ocho imágenes de cada modelo de enseñanza). Se comparó la puntuación del examen teórico con la de las imágenes clínicas. Tras el examen final, el alumno realizó un cuestionario de evaluación. Resultados. La calificación media final de las imágenes (sobre 10 puntos) fue de: 6,8 \pm 1,5 y la del test (sobre 10 puntos) fue de $7,3 \pm 0,9$. La calificación media de las imágenes expuestas en la web $(7,4 \pm 1,6)$ fue superior a la del modelo presencial $(6,3 \pm 1,7) p<0,0001$. Existía una correlación entre la puntuación total de la imagen y la del test $(r: 0,584, p<0,0001)$. Asimismo, se correlacionaba la calificación de la imagen del modelo presencial y la de la imagen expuesta en la web $(r$ : 0,697, $p<0,0001)$. Conclusiones. Las calificaciones de los casos expuestos en la web fueron superiores a las de los casos expuestos en los seminarios presenciales. La enseñanza de la patología médica a través de imágenes clínicas fue un método muy bien considerado por los alumnos.

Palabras clave. Enseñanza tradicional. Enseñanza virtual. Imágenes clínicas.
On-line learning with e-mail tutoring for clinical images is more efficient than traditional teaching methods

Introduction. The teaching of Internal Medicine through images is the key for the achievement of clinical skills in the diagnosis. Aims. To compare the efficiency of a teaching method based on images in a face-to-face learning situation with the traditional teaching methods, and to evaluate the degree of satisfaction amongst the alumni regarding the new teaching method within the Internal Medicine. Materials and methods. The study was carried out throughout the academic year 2005/06 amongst 62 Internal Medicine students in the School of Medicine in Córdoba. Two teaching methods were compared: (i) face-to-face-15 images were exposed in workshops, and (ii) distance-clinical images were exposed at the School of Medicine web site through a tutorial system based on e-mail. The evaluation consisted in a clinical evaluation of 16 images -8 images for each teaching method. The results from the multiple choice exam and the clinical images exam were also compared. Finally, students answered an assessment questionnaire. Results. The final average qualification-out of 10- for the images was: $6.8 \pm 1.5$ and for the multiple choice exam -out of 10- was $7.3 \pm 0.9$. The average qualification was higher for the images exposed at the web site than for the face-to-face model: $(7.4 \pm 1.6)$ vs (6.3 $\pm 1.7) p<0.0001$. There was a correlation between the total punctuation for the images and the examination ( $r: 0.584$, $p<0.0001$ ). Moreover, there was also a correlation between the qualification obtained for the images in the face-to-face method and the images exposed on-line ( $r: 0.697, \mathrm{p}<0.0001)$. Conclusions. Qualifications for the cases displayed on the website were higher than those for the cases exposed on the face-to-face workshops. In addition to this, students had a very positive opinion regarding the new teaching method for Internal Medicine based on clinical images.

Key words. Clinical images. On-line learning. Traditional teaching.
Departamento de Medicina, ORL y Dermatología. Facultad de Medicina. Hospital Universitario Reina Sofía. Universidad de Córdoba. Córdoba, España.

\section{Correspondencia}

Dr. Francisco Pérez Jiménez. Facultad de Medicina. Avda. Menéndez Pidal, s/n. E-14004 Córdoba.

Fax +34957010449

E-mail

fperezjimenez@gmail.com

Este trabajo es un proyecto de innovación y de mejora de la calidad docente, que ha sido financiado por el Comisionado para la Gestión de Calidad y Programas de Innovación, VII convocatoria (2005-2006). Los autores de dicho proyecto son: R.A. Fernández de la Puebla-Giménez, F. Pérez-Jiménez, A. TorresGómez, J. López-Miranda, M. de la Mata-García, J. Román-Gómez, P. PérezMartínez, R. Ruiz-Moral.

Agradecimientos A los alumnos, por su inestimable colaboración en el desarrollo de este proyecto. 


\section{Introducción}

La enseñanza tradicional de la medicina clínica se ha basado en la 'clase magistral', donde el profesor expone al alumno un tema y éste recoge información en forma de apuntes, y, ocasionalmente, utiliza libros. A veces se le ofrece un apoyo iconográfico que visualiza de modo fugaz durante la clase, sin que se evalúe. Las prácticas clínicas eran limitadas y no sistematizadas para la enseñanza de habilidades clínicas. En los últimos años, en nuestro centro se ha puesto en marcha un sistema de prácticas que incluye la enseñanza a la cabecera del enfermo y la utilización de imágenes clínicas, que se muestran en clase con seminarios presenciales. El aprendizaje de estas imágenes, que incluyen los rasgos típicos para reconocer las enfermedades más frecuentes, es clave para conseguir habilidad en el diagnóstico. Esto proporciona destreza en el reconocimiento de signos clínicos o en la interpretación de determinadas exploraciones, entre ellas la analítica, la radiología básica y el electrocardiograma.

Un buen ejemplo de la gran importancia clínica que se da a la enseñanza basada en imágenes es que la revista de mayor impacto en la formación médica en Medicina Interna, New England Journal of Medicine, ha incorporado una sección denominada 'Images in Clinical Medicine' [1], donde se incluyen dos imágenes semanales, de gran valor didáctico, acompañadas de la información clínica correspondiente, una de las cuales se publica en la web. Medicina Clínica, la revista de mayor impacto en España de la misma especialidad, también incluye semanalmente un apartado denominado 'La imagen de la semana' [2].

En los últimos años estamos viviendo un gran desarrollo de las nuevas tecnologías en medicina [3], que se hace especialmente evidente en el espacio virtual de la red y con la posibilidad de comunicarse con tanta fluidez como permite el correo electrónico. Con el empleo de estos recursos, los alumnos pueden tener acceso a imágenes clínicas de gran calidad, que se pueden completar con la información clínica correspondiente. Esto permite que el alumno pueda relacionar la historia clínica del paciente con la imagen y plantearse un diagnóstico. Por otra parte, el correo electrónico permite al profesor estar en contacto permanente con el alumno y tutorizar su formación, sin la necesidad de asistir a una clase magistral y

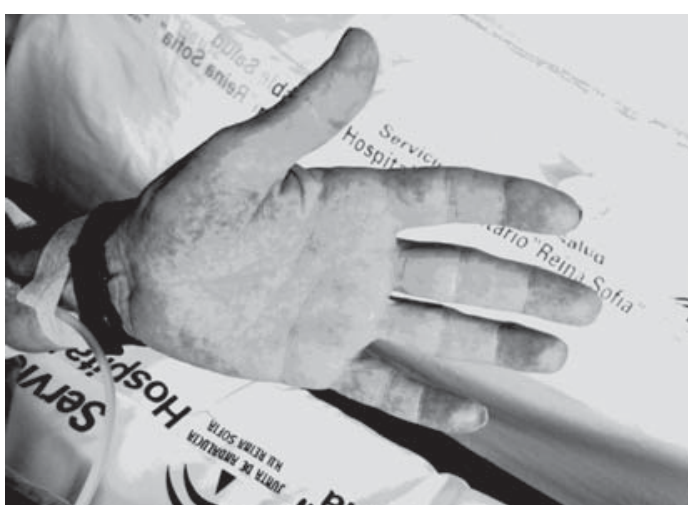

Varón de 64 años con antecedentes de etilismo crónico severo (140 gr/día de alcohol). Ingresa por ascitis y edemas en extremidades inferiores. En la analítica destacaba pancitopenia, hipoproteinemia y actividad de protrombina del $40 \%$.

¿Qué signo clínico presenta este paciente? ¿Cuál sería el diagnóstico más probable de la enfermedad? Razone la respuesta

Figura 1. Ejemplo de imagen clínica.

con la posibilidad de intercambiar información, corregir los errores del alumno y orientarle en su proceso de aprendizaje. De todo esto se deduce que hay una gran sensibilidad sobre la necesidad de superar los métodos docentes tradicionales e introducir tecnologías nuevas en la enseñanza de la medicina para conseguir una formación congruente con la demanda de la sociedad.

El objetivo principal de nuestro trabajo fue comparar la eficacia docente de un método de enseñanza de imágenes clínicas en un ámbito no presencial frente a la enseñanza tradicional en un ámbito presencial. El objetivo secundario fue evaluar el grado de satisfacción del alumno sobre este método de innovación docente en la enseñanza de la Patología médica.

\section{Materiales y métodos}

El estudio se realizó durante el curso 2005-2006 entre 62 alumnos matriculados en Patología médica I, de la Facultad de Medicina de Córdoba. Dicha asignatura incluye las disciplinas siguientes: Aparato digestivo, Neumología, Cardiología y Hematología. Se seleccionaron imágenes de signos clínicos, analítica, anatomía patológica, 


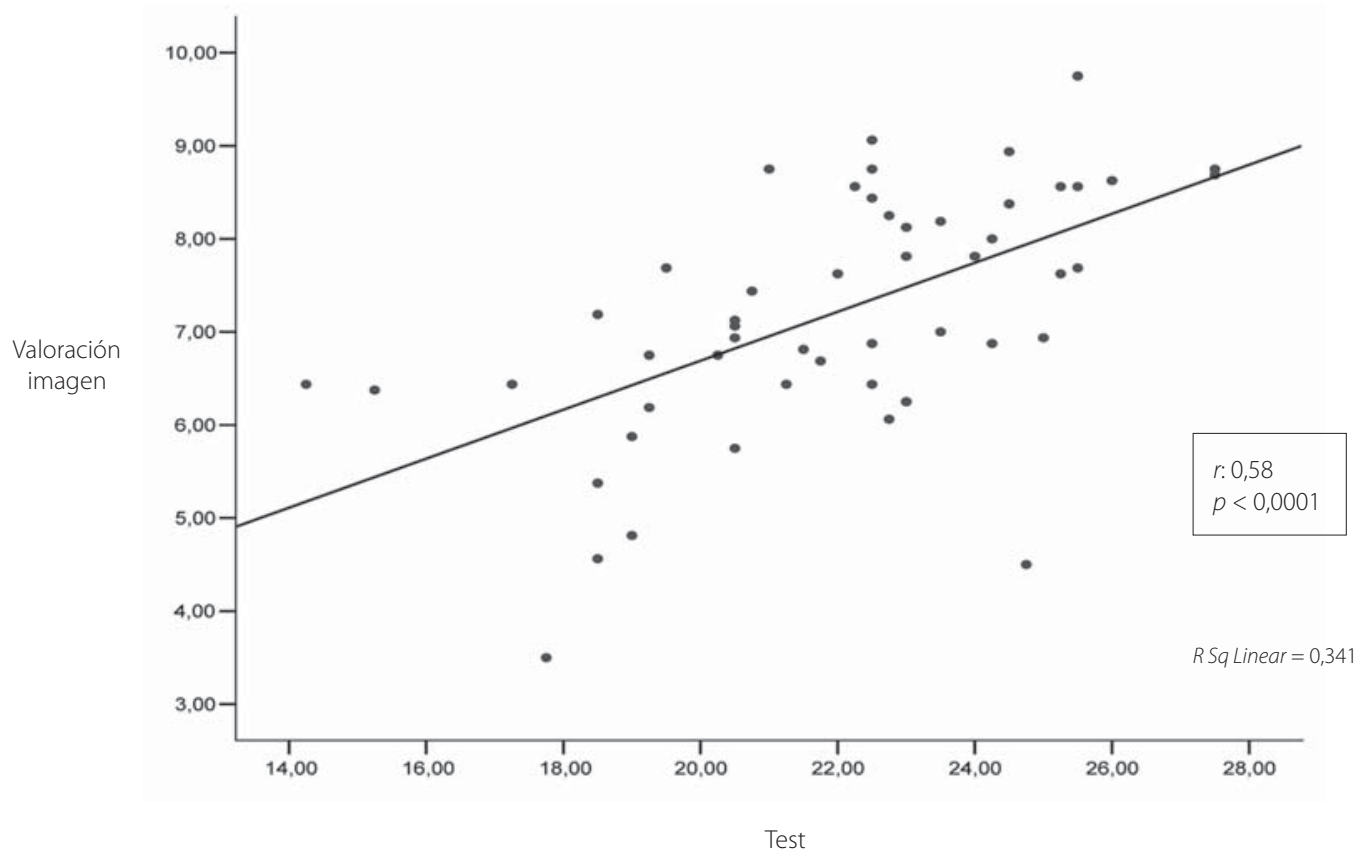

Figura 2. Correlación entre la calificación final del test y la calificación final de la imagen.

endoscopias, radiología, electrocardiografía, ecografía y tomografía axial computarizada. Cada una se acompañó de la correspondiente información clínica básica. Las imágenes con información clínica se presentaron mediante soporte PowerPoint (Fig. 1).

Se compararon dos métodos de enseñanza:

- Modelo presencial: docencia a través de imágenes clínicas por el método tradicional. En cada seminario, de 1 hora de duración, se explicaron verbalmente 15 imágenes. Se expusieron 30 imágenes por cada disciplina, hasta completar 120 imágenes.

- Modelo no presencial: docencia a través de imágenes clínicas suministradas por la red mediante la página web de la Facultad de Medicina, con tutorización a través del correo electrónico. Se colgaron 120 imágenes (30 por cada disciplina).

La selección para cada modelo (presencial frente a no presencial) se realizó de manera aleatoria.
La evaluación consistió en la valoración clínica de las imágenes de cada disciplina, con una puntuación en tres niveles: no reconocimiento de la imagen (0), reconocimiento pero sin diagnóstico (1), y diagnóstico (2). En la evaluación se seleccionaron de forma aleatoria cuatro imágenes de cada disciplina (dos del modelo presencial y dos del modelo no presencial), hasta completar un total de 16 imágenes. Para evitar sesgos, los profesores evaluadores desconocían a qué grupo pertenecía cada imagen y la puntuación la establecieron cuatro profesores independientes.

La parte teórica de la asignatura se evaluó mediante un examen tipo test de respuesta múltiple con 30 cuestiones en cada una de las disciplinas. Se comparó la calificación de la parte teórica de la asignatura con la evaluación de las imágenes clínicas. Con el objetivo de conocer la opinión de los alumnos sobre esta innovación docente, al finalizar el examen se les hizo una encuesta (Tabla I). Para el análisis estadístico se utilizó el paquete informático SPSS 11.0. 


\section{Tabla I. Cuestionario de valoración.}

1. ¿Cree que la enseñanza de la Patología médica mediante la exposición de casos clínicos con soporte iconográfico le ha sido útil para su formación práctica en Medicina interna?

- Totalmente de acuerdo

- Parcialmente de acuerdo

- Indiferente

- Parcialmente en desacuerdo

- Totalmente en desacuerdo

2. ¿Cree que la enseñanza a través de imágenes y casos clínicos es más útil que la que se realiza mediante la 'clase magistral'?

- Totalmente de acuerdo

- Parcialmente de acuerdo

- Indiferente.

- Parcialmente en desacuerdo

- Totalmente en desacuerdo

3. ¿Cree que los médicos que desarrollan habilidades en el diagnóstico por imagen tienen mayor facilidad para obtener un diagnóstico clínico correcto?

- Totalmente de acuerdo

- Parcialmente de acuerdo

- Indiferente

- Parcialmente en desacuerdo

- Totalmente en desacuerdo

4. ¿Cree que las nuevas tecnologías como internet y el correo electrónico son fundamentales en el desarrollo del diagnóstico por imagen?

- Totalmente de acuerdo

- Parcialmente de acuerdo

- Indiferente

- Parcialmente en desacuerdo

- Totalmente en desacuerdo
5. ¿Cree que el examen se ajusta a los contenidos expuestos en los seminarios y/o en la página web?

- Totalmente de acuerdo

- Parcialmente de acuerdo

- Indiferente

- Parcialmente en desacuerdo

- Totalmente en desacuerdo

6. ¿Ha presentado problemas en la obtención de las imágenes/información clínica a través de la web?

- He tenido muchos problemas

- He tenido algunos problemas

- No he tenido ningún problema

Si procede, especificar qué problemas.

7. ¿Ha tenido algún problema en la tutorización de la enseñanza con el correo electrónico?

- He tenido muchos problemas

- He tenido algunos problemas

- No he tenido ningún problema

Si procede, especificar qué problemas.

8. De 0 a 10, ¿qué puntuación daría a la calidad de los casos y de las imágenes?

9. De 0 a 10, ¿qué puntuación daría a la calidad de las explicaciones del profesor en los seminarios de este proyecto?

Tabla II. Resultado del cuestionario de valoración: preguntas del 1 al 5 (número total de estudiantes: 62).

\begin{tabular}{|c|c|c|c|c|c|}
\hline Pregunta & $\begin{array}{l}\text { Totalmente } \\
\text { de acuerdo }\end{array}$ & $\begin{array}{l}\text { Parcialmente } \\
\text { de acuerdo }\end{array}$ & Indiferente & $\begin{array}{l}\text { Parcialmente } \\
\text { en desacuerdo }\end{array}$ & $\begin{array}{l}\text { Totalmente } \\
\text { en desacuerdo }\end{array}$ \\
\hline 1 & $41(66 \%)$ & 18 (29\%) & $0(0 \%)$ & $3(5 \%)$ & $0(0 \%)$ \\
\hline 2 & $31(50 \%)$ & $21(34 \%)$ & $5(8 \%)$ & $5(8 \%)$ & $0(0 \%)$ \\
\hline 3 & $44(71 \%)$ & $16(26 \%)$ & $2(3 \%)$ & $0(0 \%)$ & $0(0 \%)$ \\
\hline 4 & $34(55 \%)$ & 15 (24\%) & $5(8 \%)$ & $8(13 \%)$ & $0(0 \%)$ \\
\hline 5 & $48(77 \%)$ & $8(13 \%)$ & $3(5 \%)$ & $3(5 \%)$ & $0(0 \%)$ \\
\hline
\end{tabular}




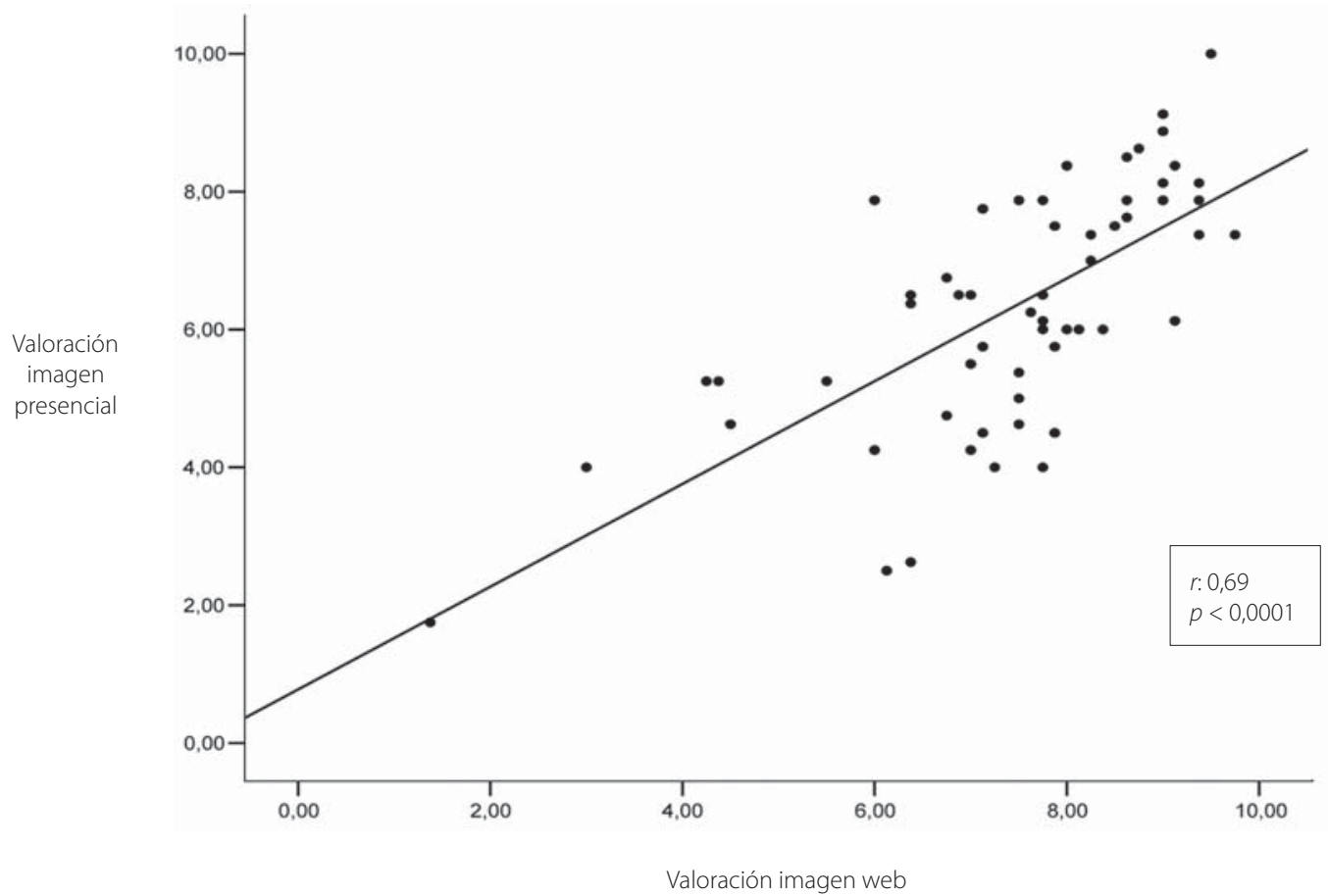

Figura 3. Correlación entre la calificación final de la imagen expuesta en la web y la calificación final de la imagen presencial.

\section{Resultados}

\section{Calificaciones}

La calificación de los alumnos en las cuatro disciplinas de Patología médica I fue la siguiente (sobre 10 puntos): Digestivo: 6,9 $\pm 1,7$; Hematología: 5,6 \pm 2,3; Cardiología: 6,4 $\pm 2,4$ y Neumología: 8,3 $\pm 1,9$. Las calificación final de las imágenes (suma de la presencial y la no presencial) fue de $6,8 \pm$ 1,5. La calificación media de las imágenes expuestas en la web $(7,4 \pm 1,6)$ fue superior a la del modelo presencial $(6,3 \pm 1,7) p<0,0001$.

La calificación media final del test (sobre 30 puntos) fue de $22 \pm 2,9$. Existía una correlación entre la puntuación total de la imagen y la del test $-r$ : 0,584, $p<0,0001-$ (Fig. 2). Asimismo, existía una correlación entre la calificación de la imagen del modelo presencial y la imagen expuesta en la web $-r$ : 0,697, $p<0,0001-$ (Fig. 3).

\section{Cuestionario de evaluación}

En la tabla II se exponen los resultados de las preguntas 1 a 5 del cuestionario de evaluación. La gran mayoría de alumnos pensaba que la enseñanza de la Patología médica mediante la exposición de casos clínicos con soporte iconográfico fue útil para su formación práctica. Asimismo, creían que la enseñanza a través de imágenes y casos clínicos es más útil que la que se realiza mediante la exposición verbal del tema. Finalmente, estaban de acuerdo en que los médicos que desarrollan habilidades en el diagnóstico por imagen tienen mayor facilidad para obtener un diagnóstico clínico correcto. Respecto al papel de las nuevas tecnologías (internet y correo electrónico), la mayoría de estudiantes manifestó que son fundamentales para el desarrollo del proceso de aprendizaje para el diagnóstico. También opinaron que el examen se ajustaba a los contenidos expuestos en los seminarios y/o en la página web. Un cuarto de los estudiantes tuvo problemas en la obtención de las imágenes a través de la web. Dichos problemas se centraron en la lentitud para conseguir las imágenes cuando utilizaban los ordenadores de la sala de informática de la Facultad de Medicina. La mayoría no tuvo ningún problema para su obten- 
ción $(71 \%)$ ni en la tutorización de la enseñanza con el correo electrónico (95\%). La puntuación media de la calidad de los casos e imágenes y de la calidad de las explicaciones del profesor en los seminarios fue de 8,4 y 8,5 , respectivamente.

Por lo que se refiere a los comentarios y las sugerencias, casi la mitad (42\%) de los estudiantes pensó que el número de casos expuestos en cada seminario era excesivo, y un cuarto (26\%) sugirió que las imágenes debían exponerse después de la teoría de la disciplina correspondiente. Para un $16 \%$, el nivel de los casos era excesivo y/o no se había expuesto en la clase teórica. Un cuarto (27\%) reflejó de forma espontánea que era una idea excelente y apoyó proyectos de innovación de este tipo.

\section{Discusión}

Nuestro trabajo demuestra que el método virtual fue superior al método tradicional en la enseñanza de las imágenes clínicas. Además, el aprendizaje de la Patología médica a través de este método estuvo muy bien considerado por el alumno. El proyecto ha servido para introducir en la Patología médica de la Facultad de Medicina un método docente innovador, que se asemeja a la actuación que tiene el médico en su práctica clínica habitual, con la asociación de los datos básicos de la historia clínica y las imágenes, para llegar a un diagnóstico clínico. El alumno ha podido adquirir habilidades en el diagnóstico a través de imágenes de enfermos reales y de exploraciones complementarias como la analítica, el electrocardiograma, la radiología, la endoscopia y la anatomía patológica. Además, hemos podido demostrar la utilidad del método de enseñanza virtual mediante la exposición de imágenes clínicas, tutorizadas por correo electrónico. La experiencia ha sido muy estimulante tanto para los profesores implicados en su desarrollo como para los estudiantes, que han visto cómo en el aula se puede aprender enseñanza clínica, con gran similitud con la práctica clínica habitual. Además, ha sido de gran utilidad para mostrar imágenes básicas que el alumno, con frecuencia, no tiene ocasión de ver en la cabecera del enfermo, debido a que el rotatorio en el hospital suele ser corto. El apoyo ofrecido por los estudiantes a la utilidad del diagnóstico por imagen y de las nuevas tecnologías en su formación clínica práctica sugiere que esta modalidad de enseñanza debería potenciarse en las fa- cultades de medicina. Una objeción significativa de los estudiantes fue que el número de casos expuestos era excesivo para el escaso tiempo disponible. Ello deberá solventarse en los próximos cursos.

Las nuevas tecnologías han irrumpido en la enseñanza de la medicina, lo que cuestiona el papel de la clase magistral tradicional [4,5]. Internet suministra al estudiante toda la información necesaria para la enseñanza de la asignatura y el correo electrónico permite resolver las dudas planteadas, y favorecer la enseñanza interactiva. Además, el estudiante puede consultar la web las veces que considere oportunas. Esto probablemente justifica que las calificaciones fueran superiores cuando las imágenes clínicas se obtuvieron a través de la web que cuando se expusieron en la clase tradicional. La red ha demostrado ser útil en la enseñanza de Odontología [6], Hematología [7] y Anatomía patológica [8], así como en la educación médica continuada [9]. En nuestro trabajo demostramos que internet y el correo electrónico son herramientas útiles en la enseñanza de la Patología médica. Recientemente, Fordis [10] comparó en facultativos la utilidad para la educación médica continuada de un método basado en internet con un método interactivo a través de talleres, y encontró que el método virtual era comparable o superior al método presencial. Aunque el diseño del trabajo difiere del nuestro en cuanto a población y contenido que se debe evaluar, este trabajo y el nuestro apoyan con fuerza el protagonismo de la enseñanza virtual. Esto contrasta con la infrautilización de la web en cursos de radiología [11].

Las calificaciones de las imágenes clínicas expuestas en la web eran incluso superiores a las obtenidas con el método presencial. Esto puede ser debido a que el alumno tiene a su disposición el material para estudiarlo en cualquier momento, mientras que en el sistema tradicional, el alumno no tiene la oportunidad de ver de nuevo las imágenes. El resultado obtenido no puede justificarse con una explicación inadecuada en el método presencial, ya que los alumnos han calificado con buena nota las explicaciones del profesado. Este resultado apoya este método de enseñanza basado en las nuevas tecnologías frente al método tradicional. Encontramos una correlación entre la calificación final del test, parte teórica de la asignatura, con la calificación final del diagnóstico por imagen. Esto podría explicarse porque los conocimientos teóricos mayores facilitan la interpretación de las imágenes clínicas. Finalmente, la 
correlación positiva entre la imagen expuesta en la web y la calificación del método presencial indica que la habilidad para el diagnóstico por imagen es paralela en el alumno con independencia de la fuente de los casos clínicos.

Dada la aceptación de la enseñanza virtual de la Patología médica en estudiantes de Medicina, hemos decidido extenderla a la enseñanza de postgrado. En este sentido, hemos lanzado un blog que está vinculado a la web del hospital y donde cada semana exponemos dos casos clínicos con imágenes. La dirección electrónica es http:// diagnosticoporimagenmi.blogspot.com/

En conclusión, nuestro grupo ha demostrado la utilidad de los recursos virtuales en la enseñanza de la Medicina Interna a través de imágenes. El proyecto de innovación docente fue claramente aceptado por los alumnos de Patología médica. Creemos que esta experiencia puede extenderse a otras disciplinas similares, pero son necesarios estudios que demuestren que la aplicación de este método de innovación docente mejora la habilidad clínica de los médicos noveles.

\section{Bibliografía}

1. Kassirer JP. Images in clinical medicine. N Engl J Med 1992; 326: 829-30.
2. Carro-Alonso B, Madariaga-Ruiz B, Sainz-Martínez JM. La imagen de la semana. Calcinosis en un paciente con esclerodermia localizada. Med Clin 2006; 127: 520.

3. Uranus S. From blackboard to whiteboard: the old style of classroom education is dead. Stud Health Technol Inform 2004; 104: 147-50.

4. Chodorow S. Educators must take the electronic revolution seriously. Acad Med 1996; 71: 221-6.

5. Brezis M, Cohen R. Interactive learning in medicine: Socrates in electronic clothes. QJM 2004; 97: 47-51.

6. Broudo M, Walsh C. MEDICOL: online learning in medicine an dentistry. Acad Med 2002; 77: 926-7.

7. Woermann U, Montandom M, Tobler A. HemoSurf an interactive haematology atlas on the world wide web. Schweiz Med Wochenschr 1998; 128: 1605-7.

8. Fenderson BA. Strategies for teaching pathology to graduate students and allied health professionals. Hum Pathol 2005; 36: 145-53.

9. Wutoh R, Boren SA, Balas EA. eLearning: a review of internet-based continuing medical education. J Contin Educ Health Prof 2004; 24: 20-30.

10. Fordis M, King JE, Ballantyne CM, Jones PH, Schneider $\mathrm{KH}$, Spann SJ, et al. Comparison of the instructional efficacy of internet-based CME with live interactive CME workshops. A randomized controlled trial. JAMA 2005; 294: 1043-51.

11. Durfee SM, Jain S, Shaffer K. Incorporating electronic media into medical student education: a survey of AMSER members on computer and web use in radiology courses. Alliance of Medical Student Educators in Radiology. Acad Radiol 2003; 10: 205-10. 
